\title{
The association between chronic kidney disease, falls, and fractures: a systematic review and meta-analysis
}

\author{
N. A. Goto ${ }^{1,2}$ (D) A. C. G. Weststrate ${ }^{3}$ - F. M. Oosterlaan ${ }^{2} \cdot$ M. C. Verhaar ${ }^{4}$ - H. C. Willems ${ }^{5} \cdot$ M. H. Emmelot-Vonk $^{2}$. \\ M. E. Hamaker ${ }^{6}$
}

Received: 14 March 2019 / Accepted: 4 October 2019/Published online: 12 November 2019

(C) The Author(s) 2019

\begin{abstract}
Patients with chronic kidney disease (CKD) are more likely to experience falls and fractures due to renal osteodystrophy and the high prevalence of risk factors for falls. However, it is not well established how great the risk is for falls and fractures for the different stages of CKD compared to the general population. The objective of this systematic review and meta-analysis was to assess whether, and in which degree, CKD was associated with falls and fractures in adults. A systematic search in PubMed, Embase, CINAHL, and The Cochrane Library was performed on 7 September 2018. All retrospective, cross-sectional, and longitudinal studies of adults (18 years of older) that studied the association between CKD, fractures, and falls were included. Additional studies were identified by cross-referencing. A total of 39 publications were included, of which two publications assessed three types of outcome and four publications assessed two types of outcome. Ten studies focused on accidental falling; seventeen studies focused on hip, femur, and pelvis fractures; seven studies focused on vertebral fractures; and thirteen studies focused on any type of fracture without further specification. Generally, the risk of fractures increased when kidney function worsened, with the highest risks in the patients with stage $5 \mathrm{CKD}$ or dialysis. This effect was most pronounced for hip fractures and any type of fractures. Furthermore, results on the association between CKD and accidental falling were contradictory. Compared to the general population, fractures are highly prevalent in patients with CKD. Besides more awareness of timely fracture risk assessment, there also should be more focus on fall prevention.
\end{abstract}

Keywords Accidental falls $\cdot$ Chronic kidney disease $\cdot$ Dialysis $\cdot$ Fracture

\section{Introduction}

Electronic supplementary material The online version of this article (https://doi.org/10.1007/s00198-019-05190-5) contains supplementary material, which is available to authorized users.

N. A. Goto

n.a.goto@umcutrecht.nl

1 Dianet Dialysis Center, Utrecht, The Netherlands

2 Department of Geriatrics, University Medical Center Utrecht, Heidelberglaan 100, 3584, CX Utrecht, The Netherlands

3 Department of Internal Medicine, Diakonessenhuis Utrecht, Utrecht, The Netherlands

4 Department of Nephrology and Hypertension, University Medical Center Utrecht, Utrecht University, Utrecht, The Netherlands

5 Department of Geriatrics, Academic Medical Center Amsterdam, Amsterdam, The Netherlands

6 Department of Geriatrics, Diakonessenhuis Utrecht, Utrecht, The Netherlands
Worldwide, chronic kidney disease (CKD) is highly prevalent, with an estimated prevalence of $7 \%$ in stages 3 to 5 and with even higher rates in the elderly population [1]. Patients with $\mathrm{CKD}$ are prone to fractures due to renal osteodystrophy. This is a complex disease which is caused by a disturbance in metabolic and hormone levels (e.g., altered levels of calcium, phosphorus, parathyroid hormone, and vitamin D) that impairs bone quality and is characterized by abnormal bone remodeling $[2,3]$. These bone abnormalities are seen in a majority of patients with CKD stage $3-5$ and in all patients requiring dialysis [4]. Therefore, it is likely that patients with mild to moderate CKD already have a higher risk of fractures and that risk of fracture increases when kidney function decreases. Fractures in patients with CKD are a serious complication and are associated with a high morbidity, mortality [5], and economic burden [6, 7].

An important risk factor for fractures are falls [8]. Falls are a result of a complex interaction of factors such as muscle 
weakness, neuropathy, polypharmacy, chronic illnesses, cognitive decline, impaired mobility, and frailty [9], of which are all highly prevalent in patients with CKD [10]. Therefore, it is likely that patients with CKD are also more prone to falls than patients without CKD. In addition to a high morbidity, mortality, and economic burden, falls can also lead to fear of falling, which can cause a decrease in physical activity and social isolation [11] and could thereby even further increase the risk of falling. Hence, although both falls and fractures seem to be important problems for patients with CKD, it is not well established how great the risk is for falls and fractures for the different stages of CKD compared to the general population.

More knowledge about the risk of falls and fractures could lead to better risk stratification, which could lead to better prevention strategies. Therefore, the objective of this systematic review is to assess whether, and in what degree, chronic kidney disease is associated with falls and fractures in adults.

\section{Methods}

\section{Search strategy and selection criteria}

We aimed to identify cross-sectional or cohort studies that investigated the association between chronic kidney disease, falls, and fractures, through a comprehensive search (from conception to September 7, 2018) of PubMed, Embase, CINAHL, and The Cochrane Library. We used the search terms chronic kidney disease (dialysis patients included), fracture, and falling, with relevant synonyms. The complete search strategy is shown in Appendix 1. No limits were applied in the search.

Two authors (NG, GW) independently screened title and abstract, removed duplicate publications, and selected studies that assessed the association of CKD and fractures or falling. Studies were also included if association estimates could be calculated from prevalence/incidence from a CKD population compared to a non-CKD population. Animal studies, studies in children, studies in very specific populations (e.g., only patients with systemic lupus erythematosus, aluminum related bone disease), case reports, systematic reviews, conference abstracts, opinion papers, and studies not published in English were excluded. Considering intervention studies could possibly influence the outcome of falls or fractures, only intervention studies in which the placebo group was assessed were included in the study. The publication retrieval was completed by cross-reference checking in Web of Science for selected articles; citations of retrieved reviews, meta-analysis, and guidelines were also screened for potentially omitted studies. A similar selection procedure as described above was followed to check for eligibility of articles that were thereby retrieved. Initial disagreements on eligibility and selection of articles were resolved by discussion and their inclusion is based on full consensus.

\section{Data extraction}

Data regarding study design and results were independently extracted by two investigators (NG and FO) for each eligible study. Items that were extracted are study design, patient selection, number of participants (dialysis, CKD), demographics (age, sex), method for estimated glomerular filtration rate (eGFR) calculation, as well as the outcomes in terms of association between CKD falling and fractures. If a study provided various measurements of eGFR, first choice was to extract data of the CKD-EPI based on serum creatinine. When this was not available, second choice was the MDRD based on serum creatinine, followed by the Cockcroft Gault (CG) (based on serum creatinine) and other measurements. Measurements of eGFR based on urinary creatinine were not included, as these made our studies less comparable. Furthermore, baseline characteristics were extracted for the whole population.

\section{Quality assessment}

The methodological quality of each of the studies was assessed independently by two reviewers (NG and FO), using the Newcastle-Ottawa quality assessment scale. This scale was adapted to create one scale for quality assessment of longitudinal studies, case-control studies, and cross-sectional studies (Appendix 2). Disagreements among the reviewers were discussed during a consensus meeting, and in case of persisting disagreement, the assistance of a third reviewer (MH) was enlisted.

\section{Data synthesis and analysis}

If baseline characteristics were not available for the whole population, these were calculated when possible. To increase comparability, we estimated unadjusted odds ratio (OR) or rate ratios using the reported number of participants or reported incidence rates for the studies in which only this information and no adjusted results were published. When multiple incidences were provided in the course of the study, the most recent incidence was used to calculate a rate ratio. Furthermore, to keep the studies as comparable as possible, when data was stratified by age, only data of all age categories of $\geq 65$ years were included $(n=2[12,13])$. To visualize the risks of falls and the various fracture types, the calculated and given association estimates were visualized in a graph. To enhance the clarity of this graph, we only included eGFR categories 60-89, 45-59, 30-44, 15-29, and $<15$.

For the meta-analysis, we summarized results for the studies that provided a hazard ratio (HR) or rate ratio for the hip 
fracture and any type of fracture group using a random-effects model using the generic inverse variance method expressed as HR with $95 \%$ confidence intervals $(95 \% \mathrm{CI})$. Heterogeneity was quantified by the $I^{2}$ statistic. All analyses were conducted using Review Manager 5.3. For the group of vertebral fractures and accidental falls the number of studies per different stage of CKD was considered too small and the studies too heterogeneous (different association estimates, different outcomes, e.g., all falls vs. only serious hospitalized fall incidents) to perform a meta-analysis.

\section{Results}

\section{Characteristics of included studies}

Our search identified 12,149 potential publications (6023 from Embase, 5490 from PubMed, 348 from CINAHL, and 288 from Cochrane). After removing 1890 duplicates and 10,220 studies for other reasons (Fig. 1), a total of 37 unique publications were included in this review. Cross reference checking yielded two additional publications.

The characteristics of the 39 included studies are summarized in Table 1. The first publication is from 2000 and the most recent from 2018. Most studies were conducted in the USA. The size of the study populations ranged from 173 to $4,099,342$ (median 5601). Most studies included elderly patients, with a me(di)an age over 65 years in most studies. Eight studies included only dialysis patients [13-20], all other studies included various stages of CKD. Ten studies focused on accidental falling [19, 21-29]; seventeen studies focused on hip, femur, and pelvis fractures [12-14, 17, 18, 20, 24, 30-39]; seven studies on vertebral fractures [12, 15, 22, 24, 31, 40, 41]; and thirteen studies focused on any type of fracture without further specification $[12,16,22,29$, 42-50].

\section{Quality assessment}

Results of quality assessment can be found in Fig. 2 and Table 1. Reviewer agreement was over $95 \%$ for all aspects. The overall quality of included articles was good with a mean score of 6.1 out of 9 (standard deviation (SD) 1.2). Especially for the studies that assessed different types of fractures, many studies did not specify if they included or excluded patients with a previous fracture $[13-15,17,18$, $22,24,35-37,40,41,46,48,50]$, and so risk of bias was often unclear regarding the definition of controls. This was also a concern with the non-response rate and rate of lost to follow-up: almost half of the studies did not report data on this. Furthermore, for the any type of fracture group, almost all studies used ICD codes without radiographic confirmation. Full details of the quality assessment can be found in Appendix 3.

Fig. 1 Flowchart diagram

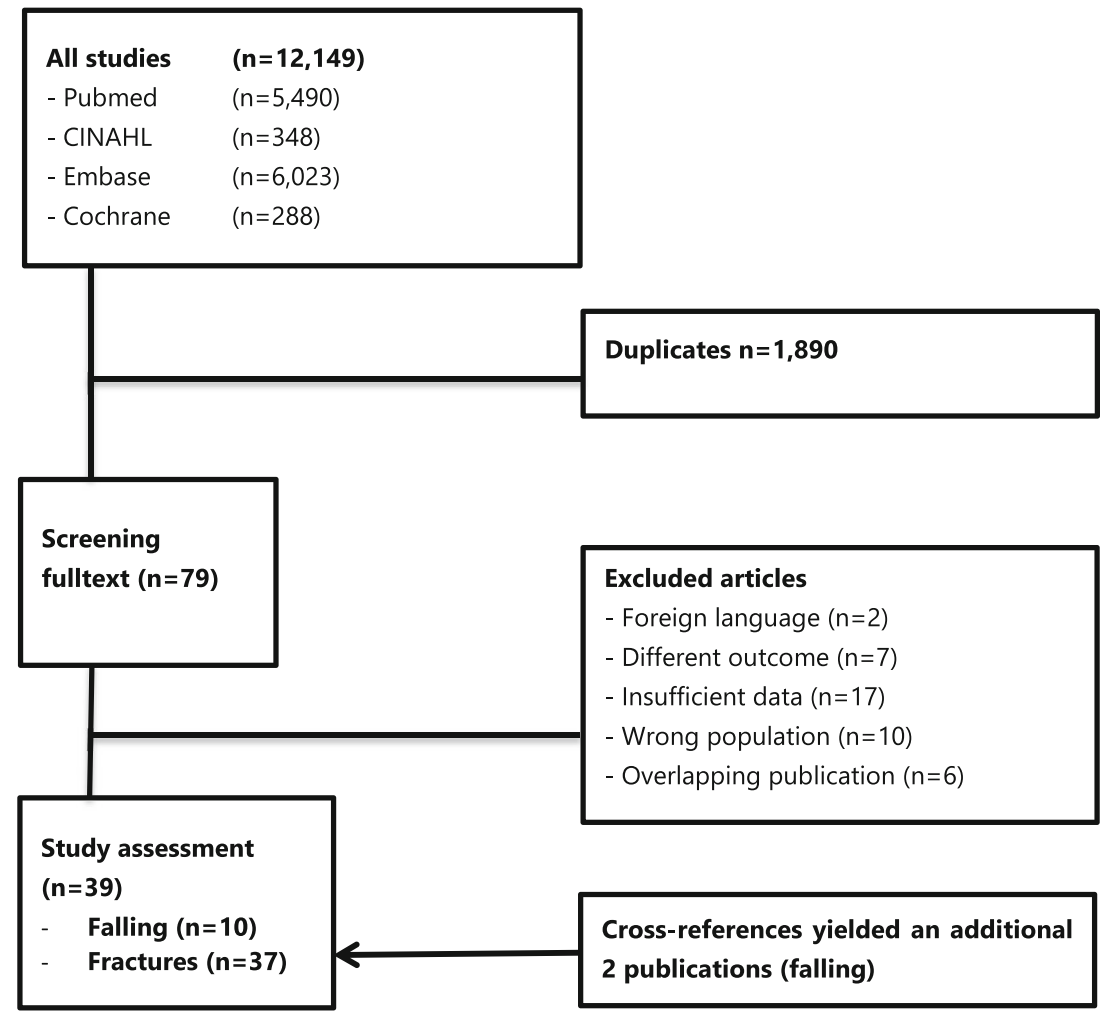




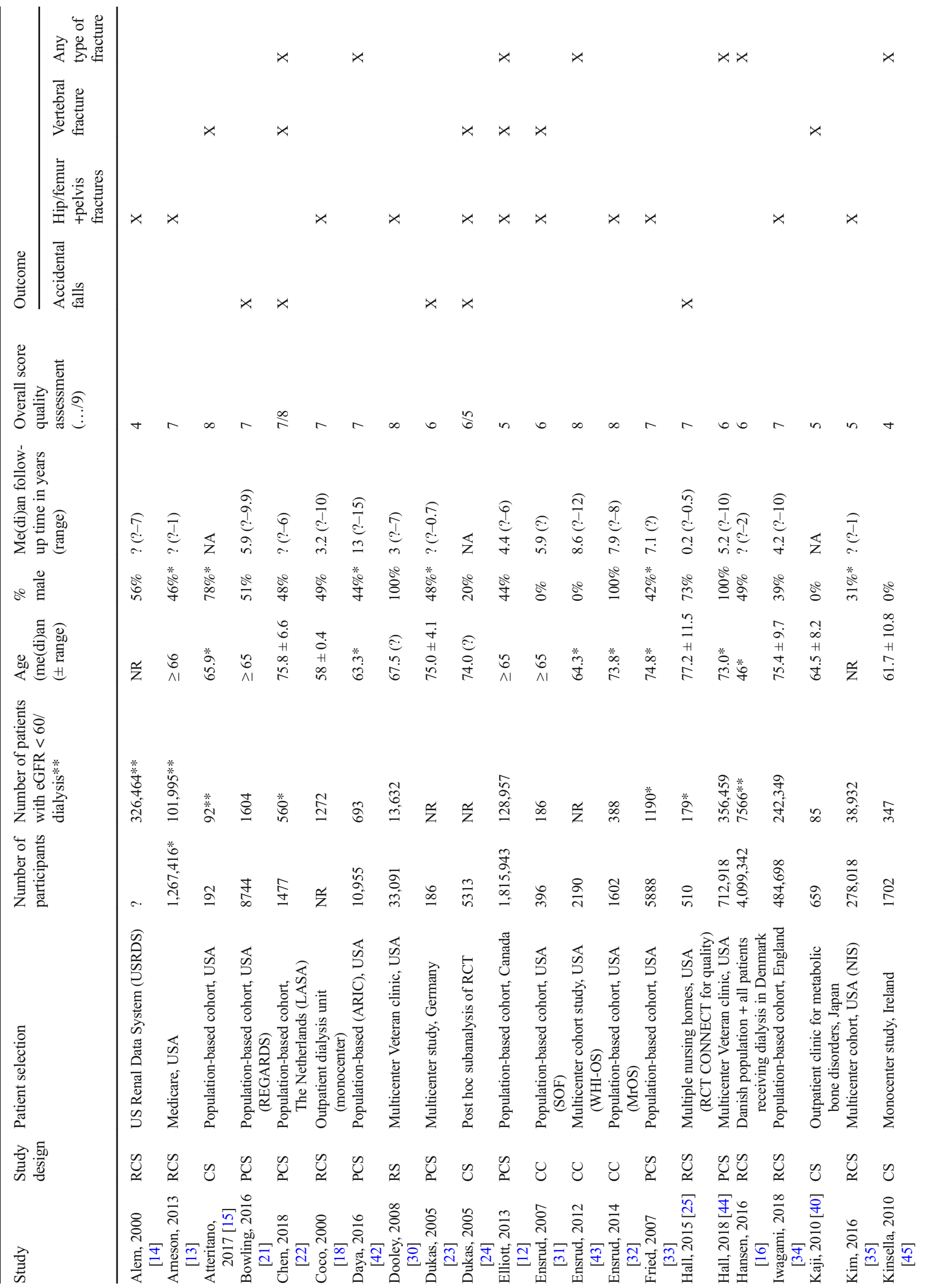




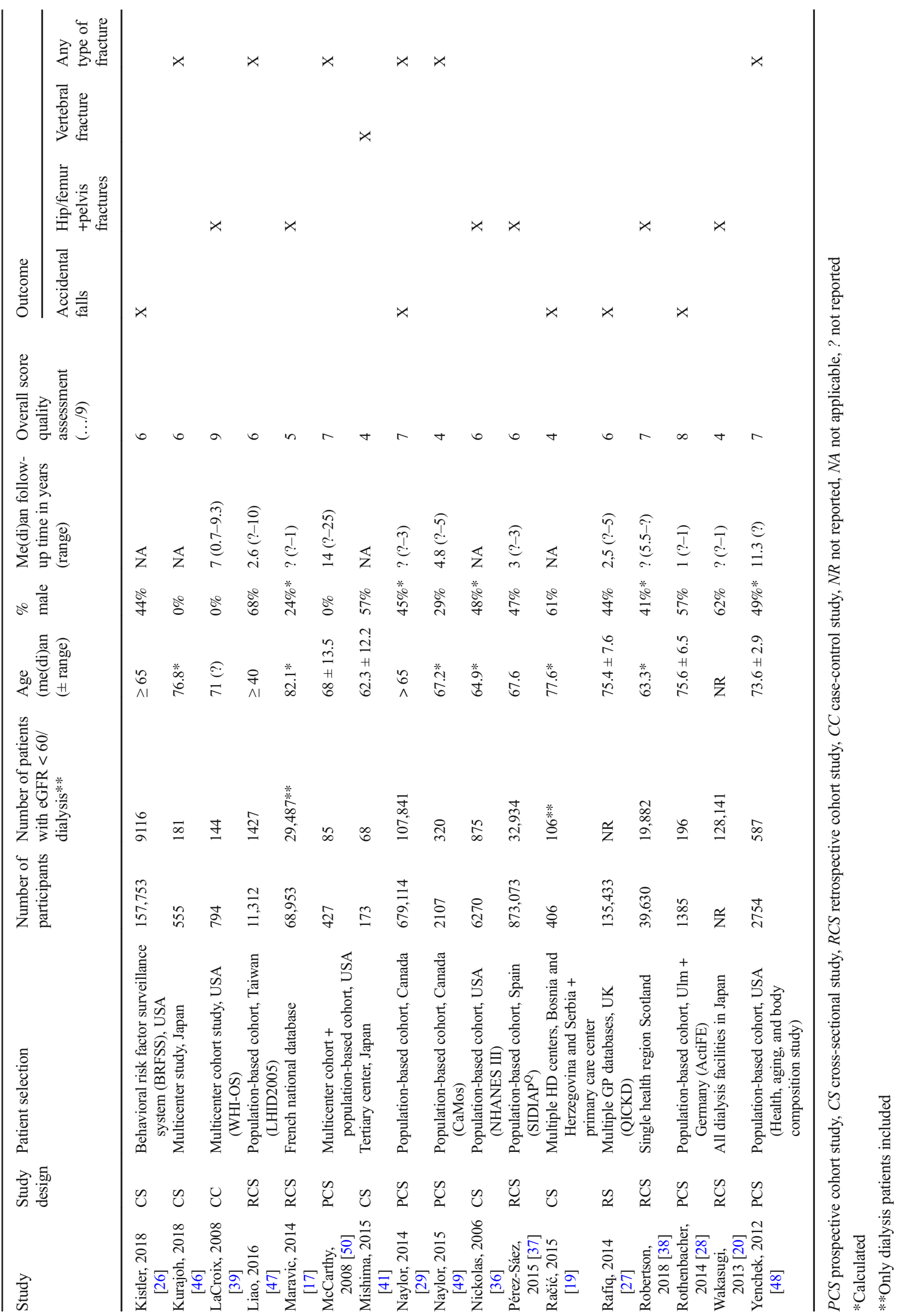


Fig. 2 Quality assessment

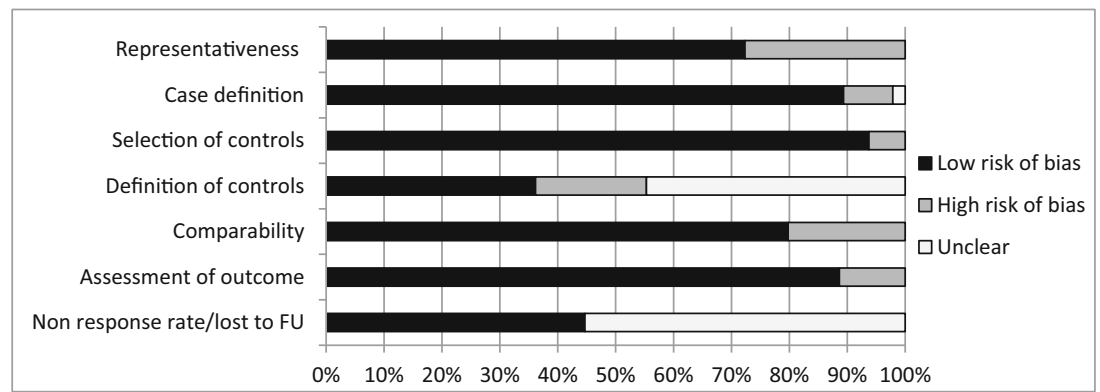

\section{Accidental falling}

Results for accidental falling are shown in Table 2 and Fig. $3 a$. Ten studies assessed the association between CKD and accidental falling [19,21-29]. Of these, five studies used an eGFR $\geq 60$ as a reference category $[19,21,25,28]$, two studies an eGFR $\geq 65$ [23, 24], one study an eGFR $>90$ [27], one study the highest quartile (eGFR $\geq 74$ ) [22], and one study compared used self-reported medical history of CKD [26]. Half of the included studies did not find an association between CKD and accidental falling [21, 22, 25, 27, 28], irrespective of CKD stage, reference category, and/or adjustment for potential confounders. The two studies that used an eGFR of $\geq$ 65 as reference both showed a significant association between a lower eGFR and falls with adjusted odds ratios ranging from 1.69 to $4.01[23,24]$. An increasing risk of accidental falling was seen with decreasing kidney function in the two studies where risk ratios were calculated from prevalence/incidence (stage $3 \mathrm{a}$ risk ratio 1.55 , stage $3 \mathrm{~b}$ risk ratio 2.00 , stage 4 risk ratio 2.39 , stage 5 risk ratio 3.45 [29], and hemodialysis risk ratio 4.7 [19], Fig. 3a). In addition, one study addressed the association between self-reported medical history of CKD and falls and found a significant association $\left(\mathrm{OR}_{\mathrm{adj}} 1.26,95 \% \mathrm{CI}\right.$ 1.13-1.47) [26].

\section{Hip fractures}

Results for hip fractures are shown in Table 3 and Fig. 3b. Seventeen studies reported on the association between CKD and hip fractures [12-14, 17, 18, 20, 24, 30-39]. Fifteen studies used an eGFR $\geq 60$ as a reference category [12-14, 17, 18, $20,30,32-38,51]$, one study an eGFR $\geq 65$ [24], and one study an eGFR > 90 [39]. Eleven out of seventeen studies found a higher risk of hip fractures for the different stages of CKD [12-14, 17, 18, 20, 34-38]. Three studies found an association for only the higher stages of CKD (eGFR $<30$ [30], eGFR < 45 [31], and < 60 [39]) and hip fractures. Furthermore, three out of seventeen studies did not find an association between CKD an hip fractures [12, 32, 33]; although one study did show an increasing rate ratio when kidney function decreases, no association was seen between
CKD and hip fracture when adjusted for potential confounders [12]. Generally, risks were increased when kidney function decreased $[12,31,38]$, with the highest fracture risks in stage 5/dialysis [13, 14, 17, 18, 20, 35] (Fig. 3b).

\section{Vertebral fractures}

Results for vertebral fractures are shown in Table 4 and Fig. 3c. Seven studies reported on vertebral fractures and CKD $[12,15,22,24,31,40,41]$. All but one study [24] used an eGFR of $\geq 60$ as the reference category. Four out of seven studies found a higher risk of patients with CKD of developing vertebral fractures, compared to the non-CKD population $[15,24,40,41]$. Furthermore, two other studies found a higher risk of vertebral fractures for patients with CKD, but when adjusted for potential confounders this risk was fully attenuated $[12,31]$. This effect was not seen in the remaining study that did not found an association at all [22].

\section{Any type of fracture}

Results for any type of fracture are shown in Table 5 and Fig. $3 \mathrm{~d}$. Thirteen studies reported on incident fractures of any type and CKD [12, 16, 22, 29, 42-50]. Six studies used an eGFR $\geq$ 60 as reference category $[12,22,29,44,48,49]$, two studies a reference category of $\geq 90[42,43]$, one study a reference category of 75-89 [45], two studies did not specify their reference category (no CKD/general population) [16, 47], and two studies assessed the association between fractures in a continuous way [46, 50]. Eight out of thirteen studies found a higher risk of fractures when eGFR decreased $<60 \mathrm{ml} / \mathrm{min} /$ $1.73 \mathrm{~m}^{2}[16,22,29,43-45,48,49]$. Two studies found an increasing rate ratio, but when adjusted for potential confounders, this was fully attenuated $[12,42]$. The three remaining studies that did not find an association studied very mild CKD (eGFR 60-90) [50], assessed eGFR in a continuous way [46] or did not specify their reference group [47]. In all included studies where multiple CKD stages were included, the risk of fractures increased when eGFR worsens [12, 22, 29, 43-45] (Fig. 3d). 


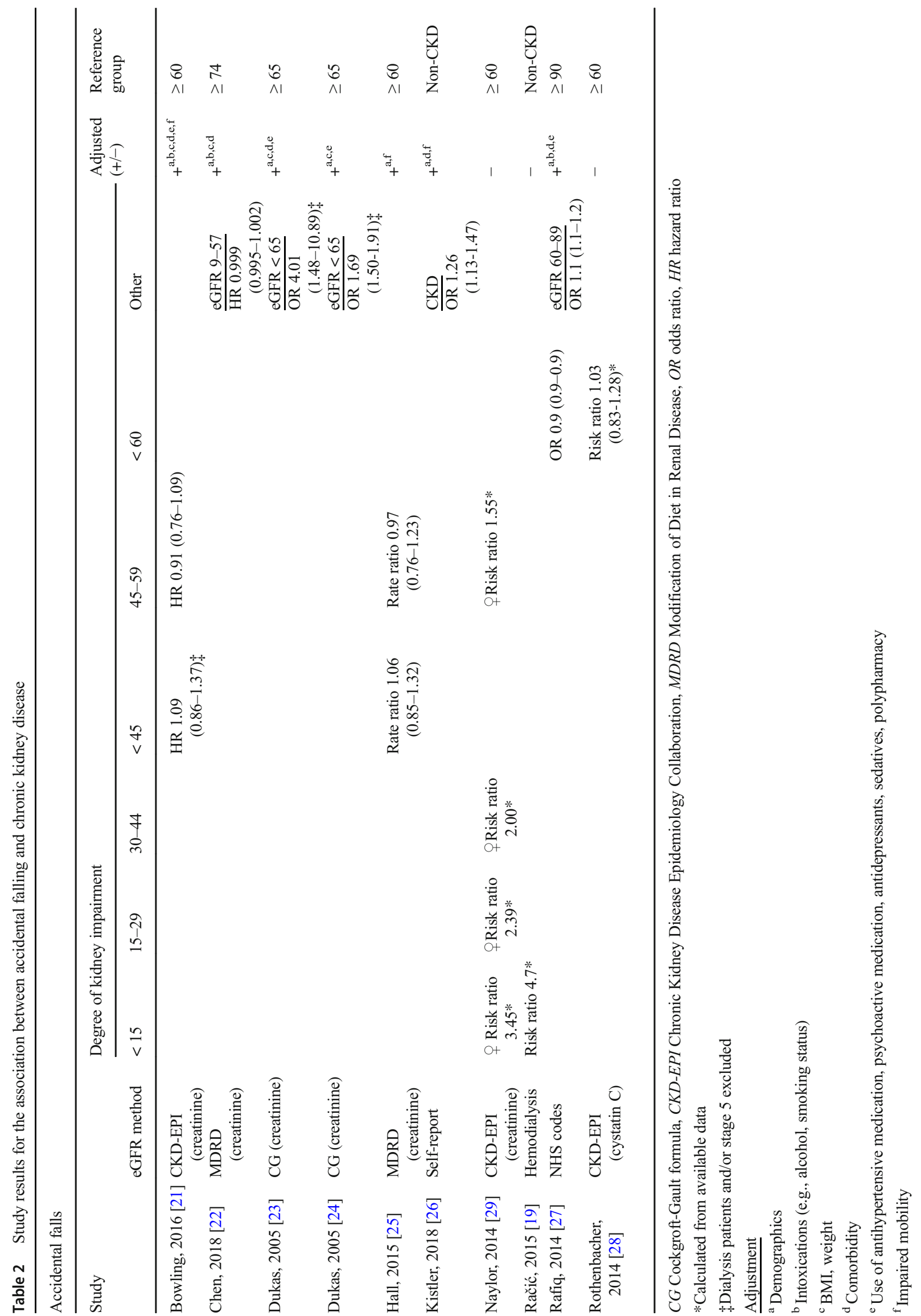



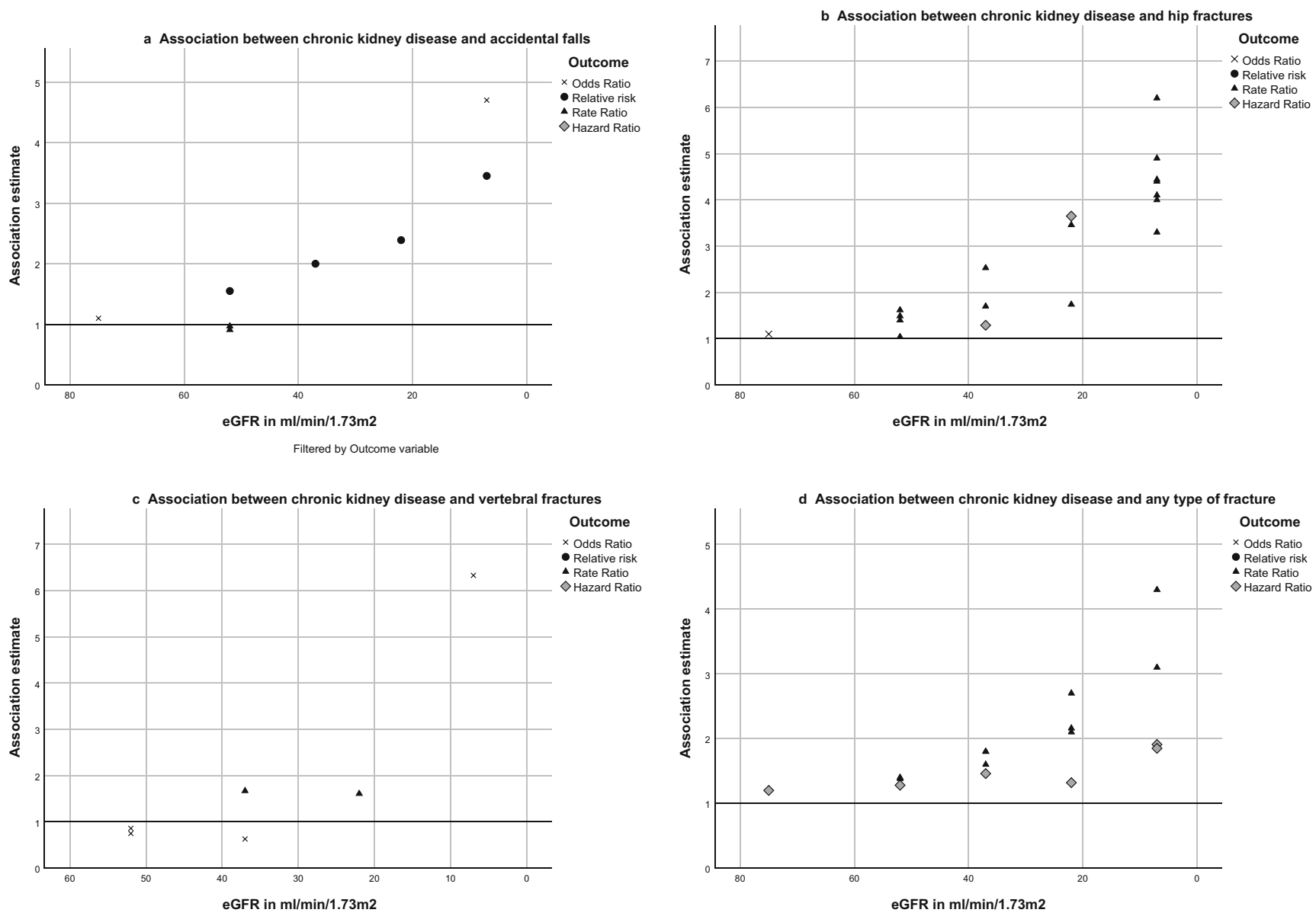

Fig. 3 a-d Association between chronic kidney disease, accidental falls (a), hip fractures (b), vertebral fractures (c), and all fractures (d)

\section{Meta-analysis}

For the hip fracture outcome, all studies that provided a hazard ratio or from which a rate ratio with $95 \% \mathrm{CI}$ could be calculated were summarized in a meta-analysis (Fig. 4a). Subsequently, three studies were excluded because they only provided an odds ratio $[24,36,39]$ and three studies were excluded because no $95 \%$ CI could be calculated [13, 17, 35]. All excluded studies found an association between CKD and hip fractures [13, 17, $24,35,36,39]$. All studies that were included into the metaanalysis assessed older adults (mean age of 63 years and older) $[12,14,20,30,32-34,37,38]$. Only in the largest study, which consisted of 1,815,943 patients, adjusted rate ratios were not reported [12]. There was a significant association between fractures and eGFR category $<60,30-44,15-29$, and $<15$. For the eGFR category of 45-59, there was a borderline association with a pooled HR of 1.36 (95\%CI 0.99-1.86). There was a graded risk, with higher risk among the more severe stages of CKD. However, the heterogeneity among the estimates was large (in most subgroups $I^{2} \geq 90 \%$ ).

Also for the any type of fracture outcome, all studies that provided a hazard ratio or from which a rate ratios with $95 \% \mathrm{CI}$ could be calculated are summarized in a meta-analysis (Fig. 4b). Two studies were excluded because they only provided odds ratios [45, 46], and two studies were excluded because they only provided risk ratios $[48,49]$. As only one study assessed CKD in a continuous way with a hazard ratio as outcome [50], a meta-analysis for this outcome was not considered feasible. Half of the excluded studies did not find an association between mild stages of CKD and fractures [45, 46, 50]. In the studies that were included into the meta-analysis, mean age ranged from 46 [16] to 75.8 years [22]. Furthermore, two of the included studies rate ratios could not be adjusted for potential confounders $[12,29]$. In the meta-analysis, there was a significant association between fractures and eGFR categories $45-59,30-44,15-29$, and $<15$. The risk was higher in more severe stages of CKD, with the highest risk in patients with an eGFR $<15$ (pooled HR of 2.63 (95\%CI 1.74-3.98). However, the heterogeneity was large, especially in the more severe stages of CKD (stage 4 and $5, I^{2} 94 \%$ and $I^{2} 98 \%$, respectively).

\section{Discussion}

In this systematic review, we found that a lower eGFR is associated with a higher fracture risk. This effect was the most 


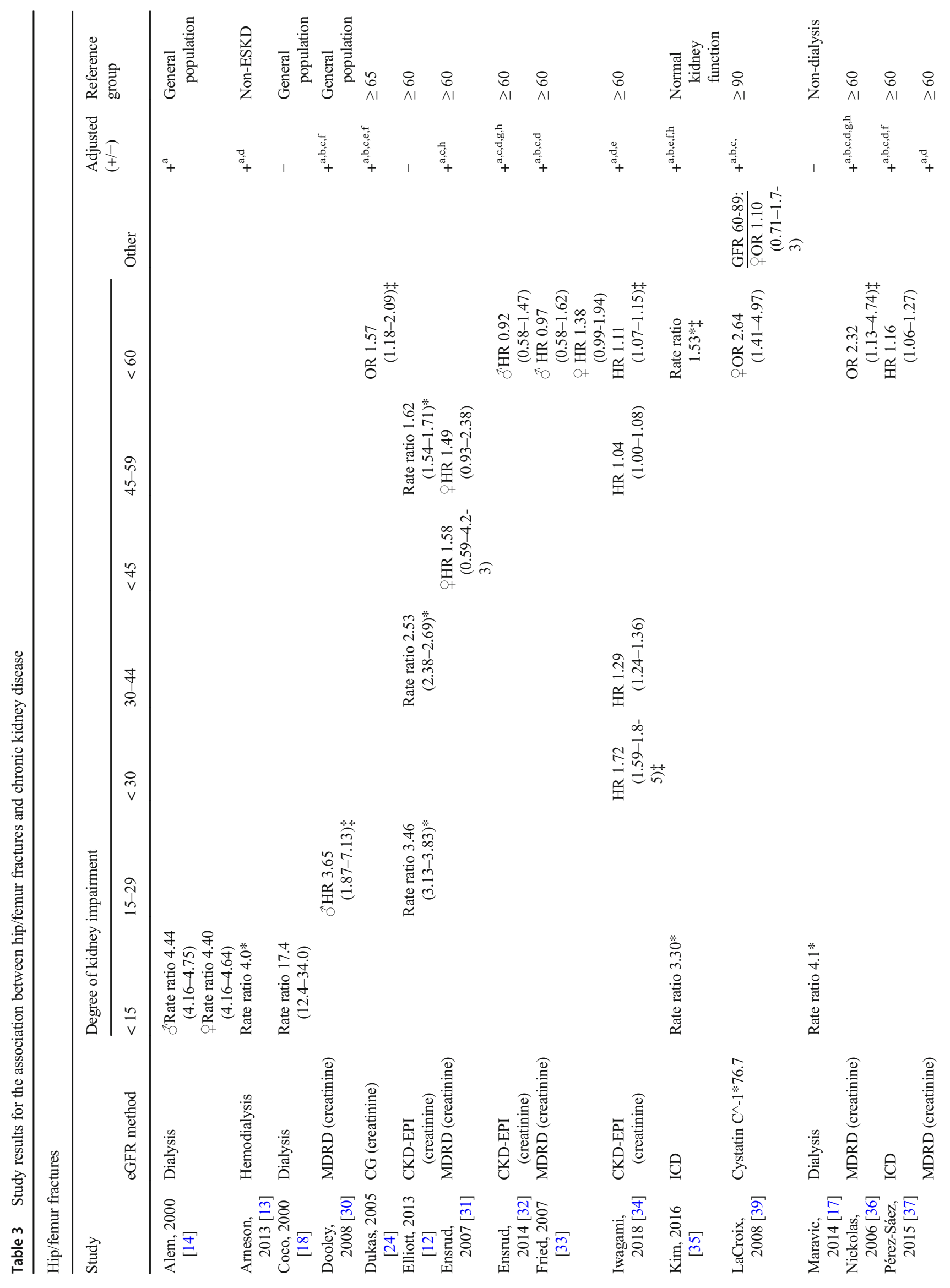




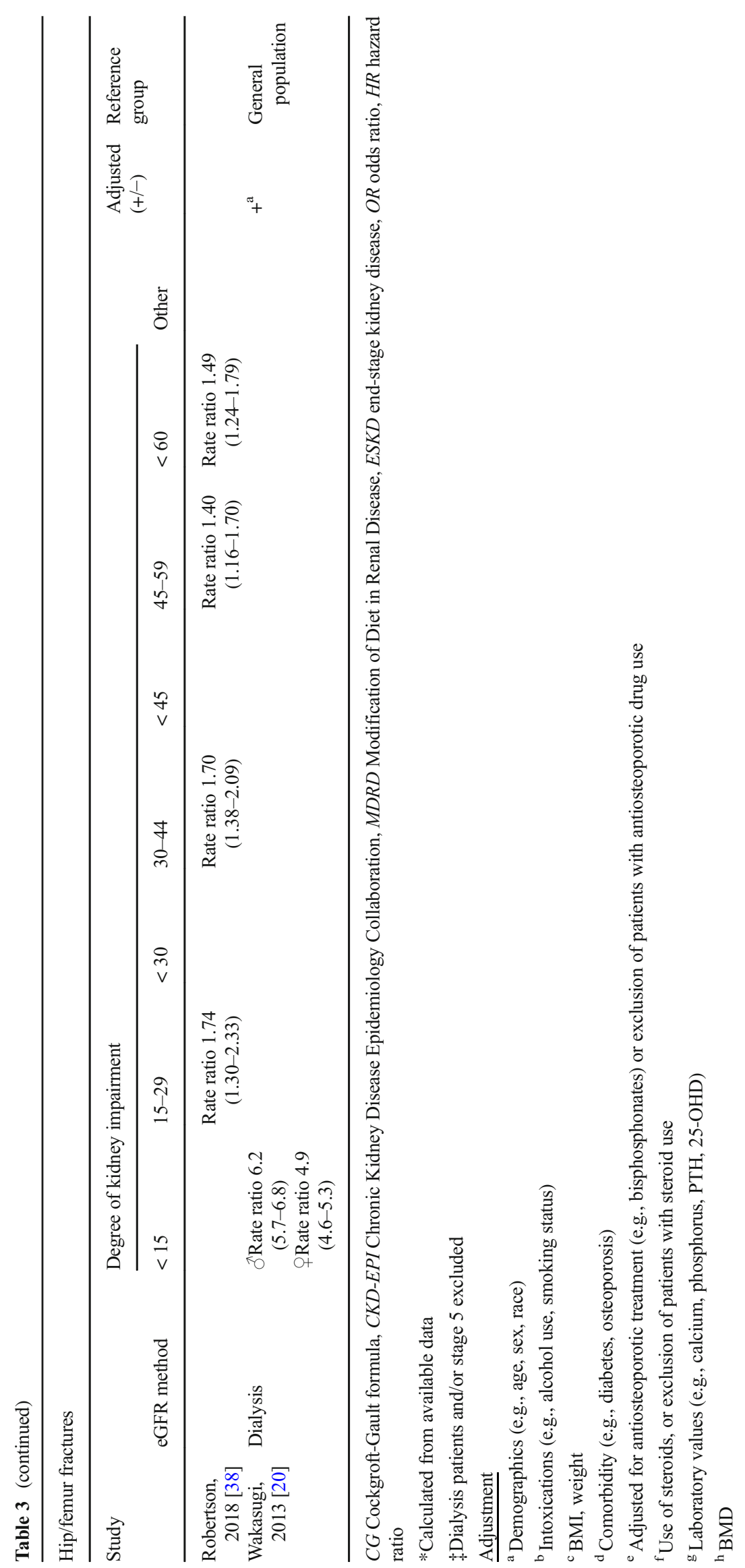




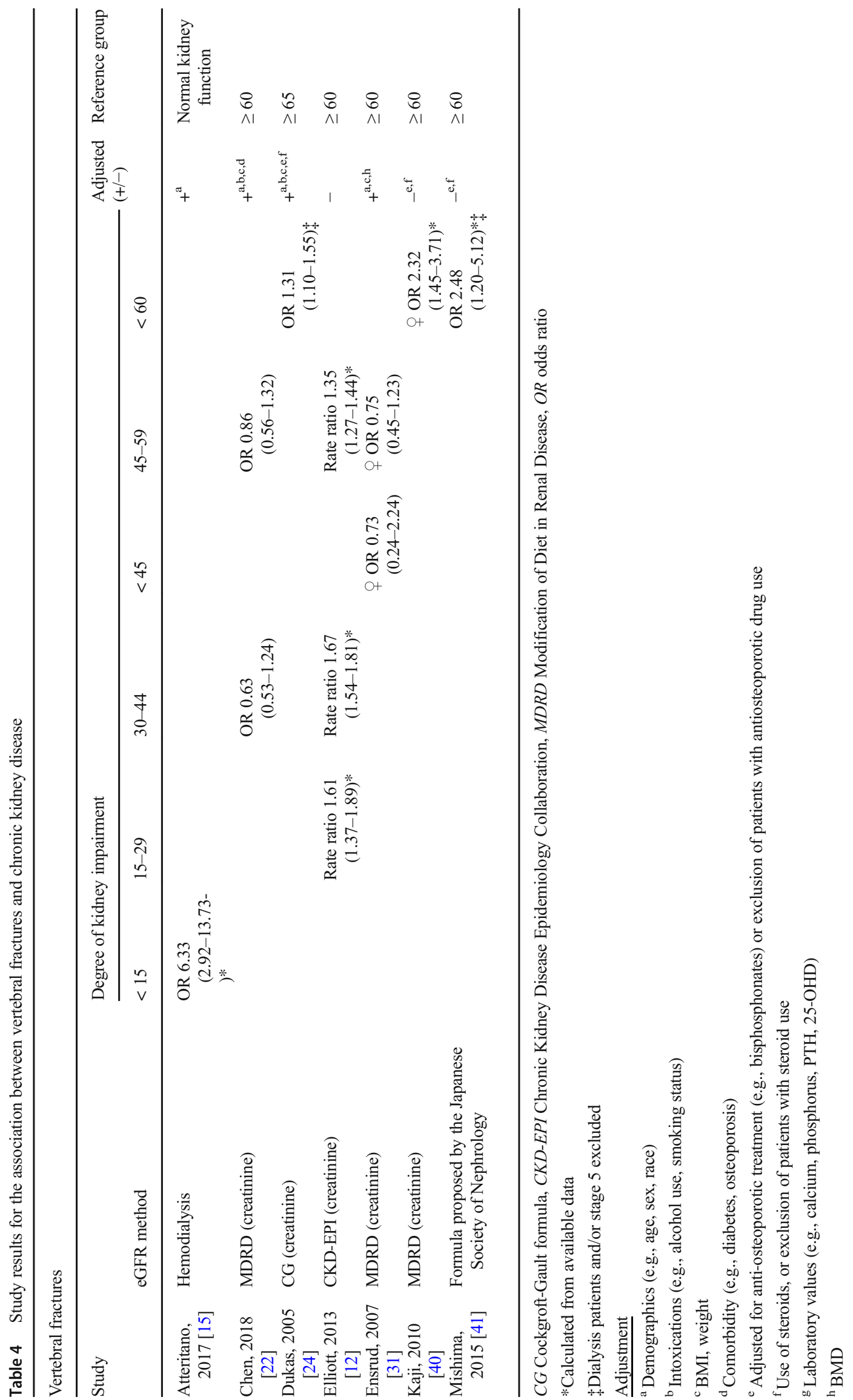




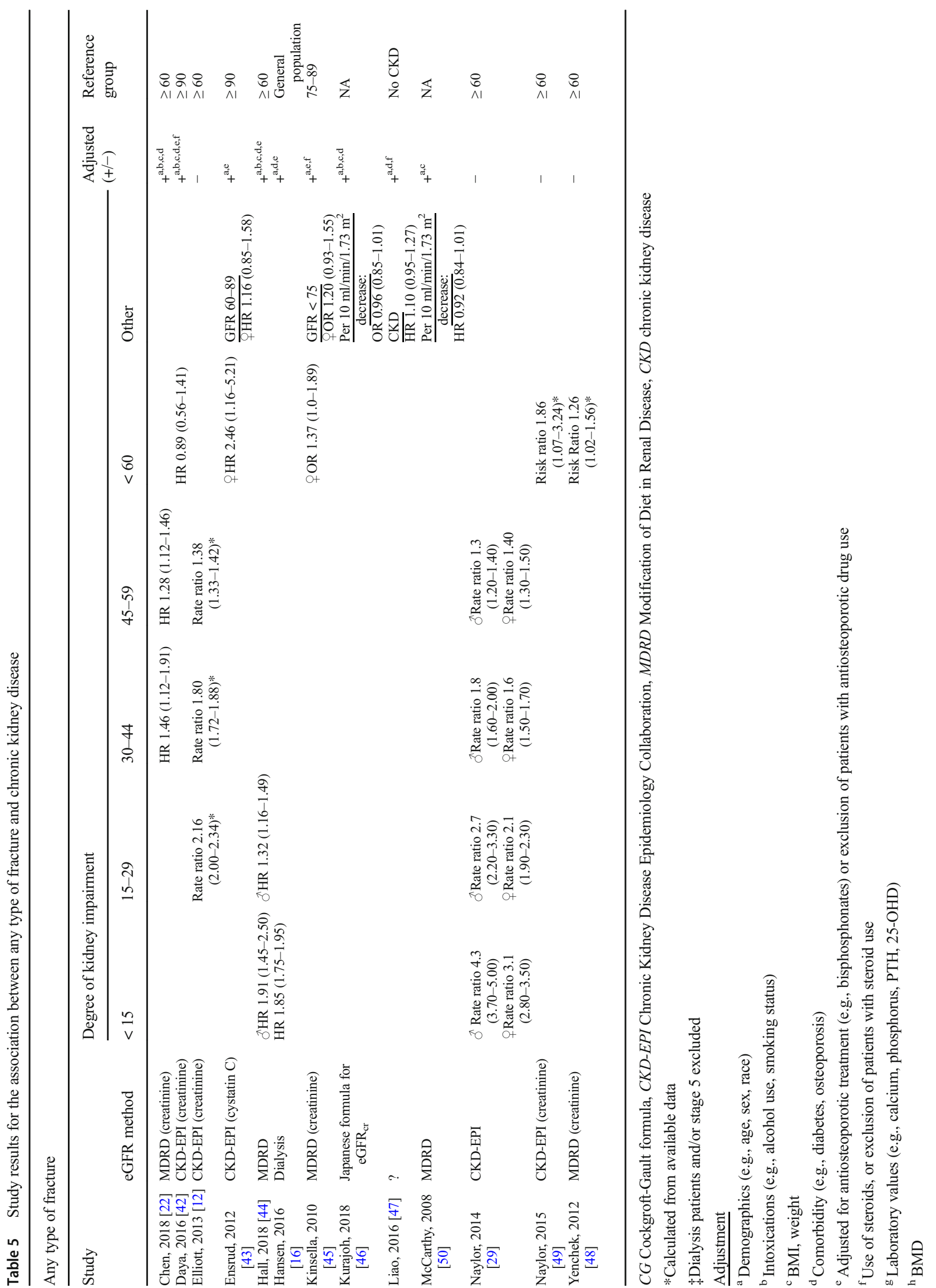


a

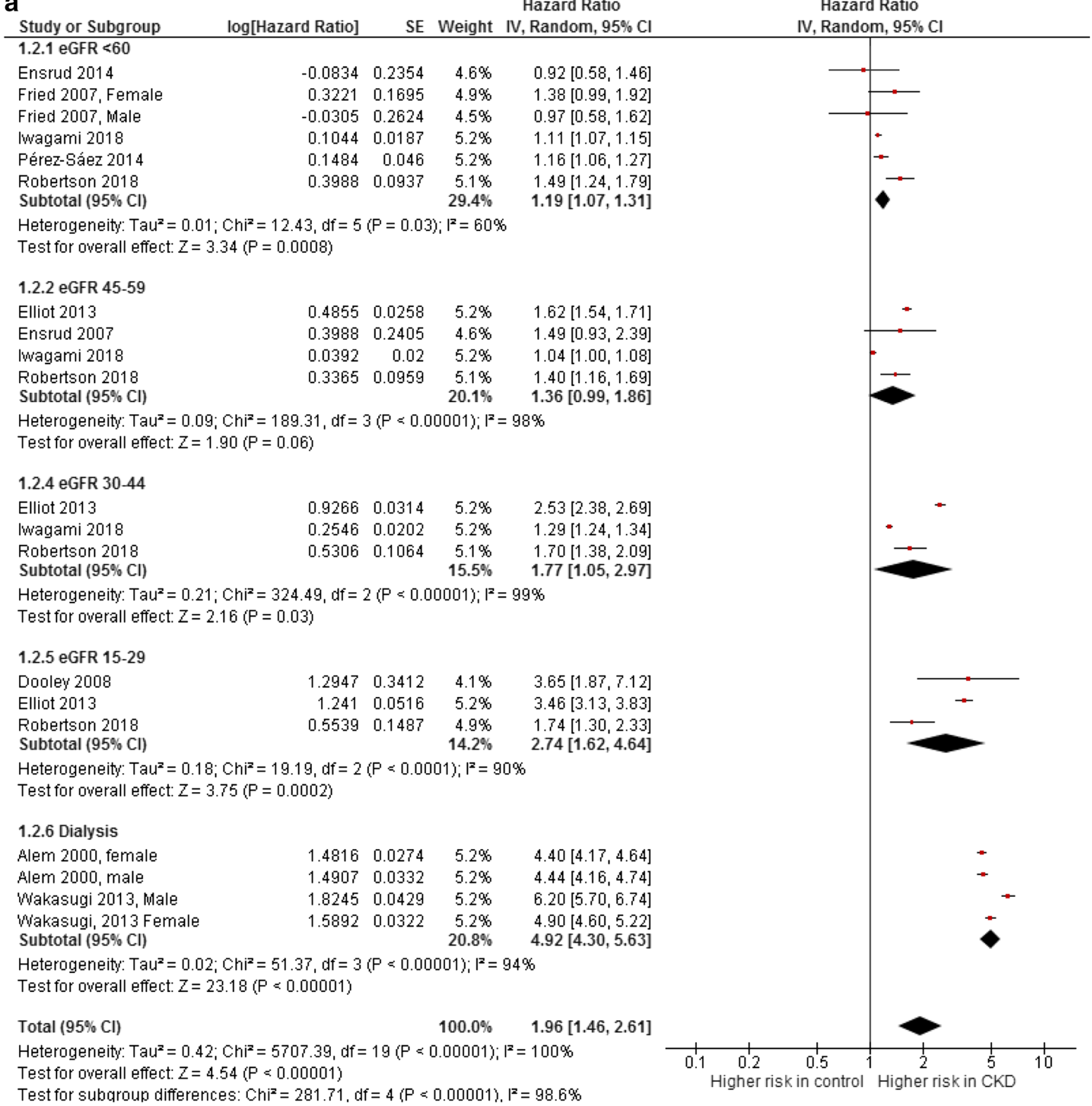

Fig. 4 a Associations of chronic kidney disease with incidence of hip fractures. b Associations of chronic kidney disease with any type of fracture

pronounced for the hip fractures and the any type of fracture group. Furthermore, the risk is higher when kidney function worsens, and starts approximately at an eGFR of $<60$ (Fig. $3 \mathrm{a}-\mathrm{d}$ and Fig. 4). For the association between a decreased eGFR and accidental falling, the evidence is contradictory.

The findings that we report on fractures support our hypothesis that a decreasing eGFR is associated with a higher fracture risk. Moreover, almost all studies that assessed patients with stage 5 found that CKD is an independent risk factor for fractures with pooled hazard ratios of 4.9 for hip fractures and 2.6 for the any type of fracture group. This is in line with previous studies that showed that even in early stages of CKD, and in almost all patients with stage 5 , an abnormal bone histology was found [52]. Although there were only a limited number of studies that assessed vertebral fractures, it is interesting that this risk seems to be lower compared to the hip and any type of fracture group. One possible explanation for these lower relative risks could be that half of the 


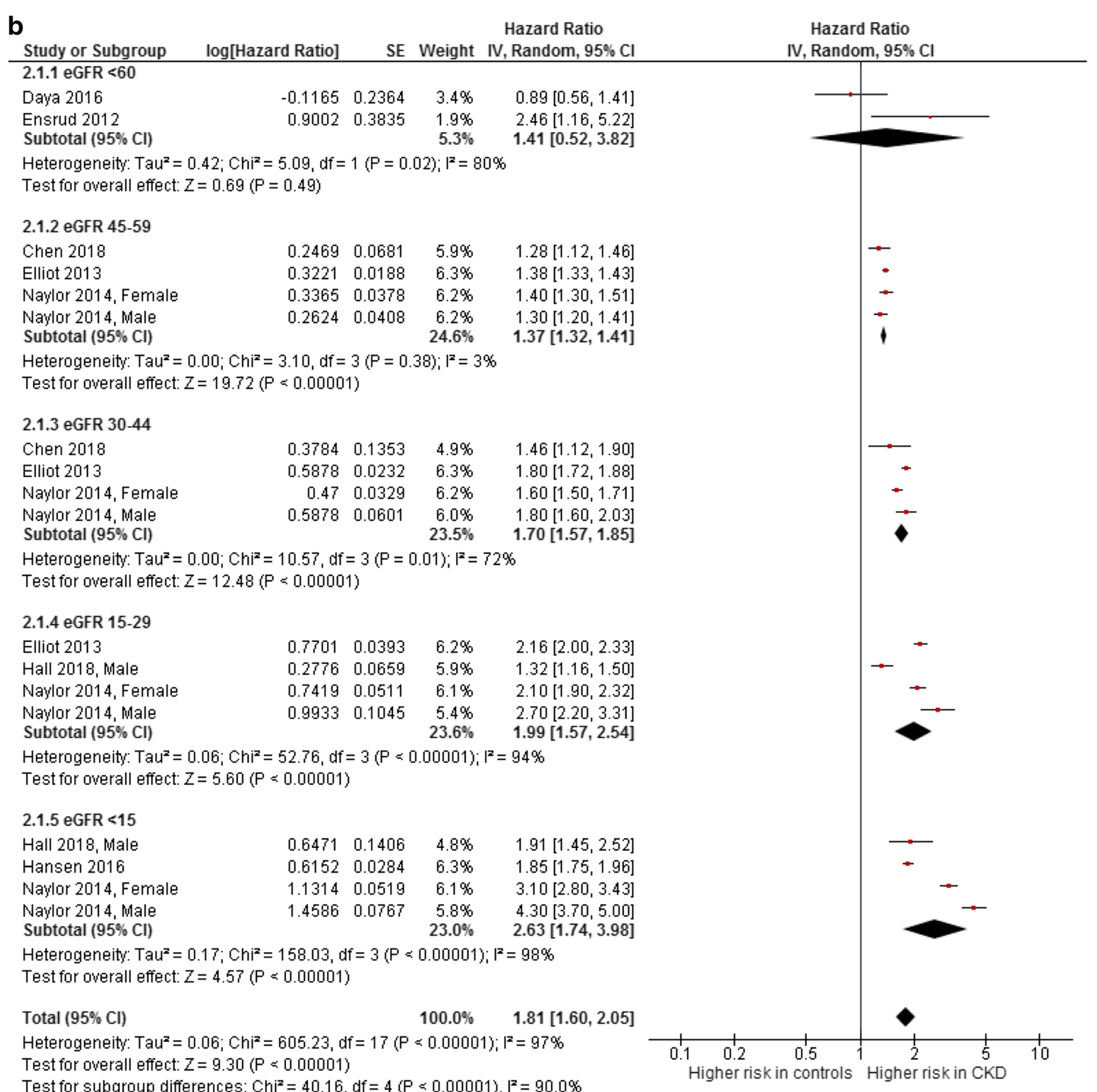

Fig. 4 (continued)

studies used ICD codes or medical history to diagnose vertebral fractures [12, 24, 31]. Prior research showed that approximately two thirds of vertebral fractures remain unnoticed as they are frequently asymptomatic [53]. Thus, it is likely that fractures are missed in studies that used ICD codes and/or medical history to diagnose vertebral fractures, and therefore, a potential difference between vertebral fractures in patients with CKD and patients without CKD.

In general, there was a graded risk for falls when kidney function worsens (Fig. 3a). However, half of our studies did not find an association between CKD and accidental falling.
One possible reason that some studies did not found an association between falls and CKD is that they adjusted their results for multiple confounders. There are several reasons why patients with CKD could fall more often compared to patients without CKD. First, CKD is frequently caused by hypertension and diabetes, which are both associated with falls [54, 55]. Second, CKD and treatment for optimization of CKD can lead to risk factors of falling. For example, due to inflammation and malnutrition, patients with CKD are more prone for muscle degeneration [56], which could lead to instability and falls. Furthermore, medication (e.g., ACE inhibitors) that is 
frequently administrated to patients with CKD could lead to postural hypotension, which is also a risk factor for falls. Third, CKD is more common in the elderly population, which is also an important risk factor [9]. Subsequently, this could mean that patients with CKD fall more often because of their risk profile, and not primarily because they have CKD.

Risks could also have been influenced by the type of measurement of eGFR. To keep our study results as comparable as possible, we chose to use the most frequently used measurements to estimate GFR (CKD-EPI, MDRD, and CG based on serum creatinine). However, serum creatinine is dependent on muscle mass, which could lead to a false-negatively low serum creatinine due to low muscle mass and therefore relatively "good" eGFR in the frail elderly [42]. This could potentially have led to a higher fracture rate in the better eGFR ranges. Another method to estimated eGFR in this population could be the use of cystatin $\mathrm{C}$ which is independent of muscle mass. For example, two studies did not found an association for eGFR based on creatinine, but did found an association between eGFR based on cystatin $\mathrm{C}$ and any type of fracture [42, 46]. On the other hand, another study that compared both methods did not find any difference for the association between CKD and hip fractures [32]. More research is needed to explore the differences in outcome when using cystatin $\mathrm{C}$ compared with serum creatinine.

As patients with CKD have much higher rates of fractures compared to the non-CKD population, it is very important to screen these patients timely for potential risk factors. For fractures, the updated Kidney Disease: Improving Global Outcomes (KDIGO) guideline recommends "BMD testing to assess fracture risk in patients with CKD stage 3 a to 5 with evidence of CKD-BMD and/or risk factors for osteoporosis, if results will impact treatment decisions [57].” This could mean that in clinical practice, much more frequent BMD measurements should be done in patients with CKD, especially in the elderly with previous falls. Furthermore, as treatment of renal osteodystrophy is very complicated in the advanced stages of CKD due to the heterogeneity of the illness and the limited experience with different treatments, and most of the lowenergetic fractures in patients older than 50 years are caused by a fall $[22,58]$, it is also very important to prevent and lower the risks of falling as much as possible. Prior research has shown that most patients who experienced a fall did not mention this to their healthcare provider [59]; therefore, it is necessary for nephrologists and general practitioners to actively ask about previous falls in patients with CKD. At this moment, there is no clear recommendation from the KDIGO guidelines to screen for accidental falling or to start interventions in patients with high risk of fracture (or falls). This could be important as it can potentially prevent morbidity and even mortality, as various studies showed that multiple interventions are able to lower the risk of falling in patients with CKD [60-62].
This systematic review provides valuable information about the fracture and fall risk of patients with $\mathrm{CKD}$, but it has several limitations. Included studies were heterogeneous, assessing different CKD stages, different eGFR methods, different definitions for falls and fractures, and different methods to measure the outcome. Therefore, a meta-analysis could not be performed for the outcome of vertebral fractures and accidental falls. Second, most studies were performed in elderly patients. Although we also presented some evidence for the younger patients, this evidence was scarce and our findings can possibly not be fully extrapolated to the younger CKD population. However, considering falls and fractures, elderly are most at risk and therefore identification in this population could lead to the highest benefit. Third, considering nonEnglish manuscripts were excluded what could potentially have led to publication bias.

In conclusion, fractures are very common in the CKD population and the risk increases when kidney function worsens. Besides more awareness of timely fracture risk assessment, there also should be more focus on fall prevention.

\section{Compliance with ethical standards}

\section{Conflicts of interest None.}

Open Access This article is distributed under the terms of the Creative Commons Attribution-NonCommercial 4.0 International License (http:// creativecommons.org/licenses/by-nc/4.0/), which permits any noncommercial use, distribution, and reproduction in any medium, provided you give appropriate credit to the original author(s) and the source, provide a link to the Creative Commons license, and indicate if changes were made.

\section{References}

1. Zhang Q-L, Rothenbacher D (2008) Prevalence of chronic kidney disease in population-based studies: systematic review. BMC Public Health 8(1):117

2. Moorthi RN, Moe SM (2013) Recent advances in the noninvasive diagnosis of renal osteodystrophy. Kidney Int 84(5):886-894

3. Damasiewicz MJ, Nickolas TL (2018) Rethinking bone disease in kidney disease. JBMR Plus 2(6):309-322

4. Coen G, Ballanti P, Bonucci E, Calabria S, Costantini S, Ferrannini M, Giustini M, Giordano R, Nicolai G, Manni M, Sardella D, Taggi F (2002) Renal osteodystrophy in predialysis and hemodialysis patients: comparison of histologic patterns and diagnostic predictivity of intact PTH. Nephron. 91(1):103-111

5. Nitsch D, Mylne A, Roderick PJ, Smeeth L, Hubbard R, Fletcher A (2009) Chronic kidney disease and hip fracture-related mortality in older people in the UK. Nephrol Dial Transplant 24(5):1539-1544

6. Schumock GT, Sprague SM (2007) Clinical and economic burden of fractures in patients with renal osteodystrophy. Clin Nephrol 67(4):201-208

7. Doan QV, Gleeson M, Kim J, Borker R, Griffiths R, Dubois RW (2007) Economic burden of cardiovascular events and fractures among patients with end-stage renal disease. Curr Med Res Opin 23(7):1561-1569 
8. Jadoul M, Albert JM, Akiba T, Akizawa T, Arab L, Bragg-Gresham JL, Mason N, Prutz KG, Young EW, Pisoni RL (2006) Incidence and risk factors for hip or other bone fractures among hemodialysis patients in the Dialysis Outcomes and Practice Patterns Study. Kidney Int 70(7):1358-1366

9. World Health Organization. WHO global report on falls prevention in older age. Community Health (Bristol) [Internet]. 2007;53. Available from: http://www.who.int/ageing/publications/Falls prevention7March.pdf. Accessed 1/3/2018

10. Bowling C, Booth JN, Gutierrez OM, Kurella Tamura M, Judd S, Warnock D et al (2014) Nondisease-specific problems and all-cause mortality among older adults with chronic kidney disease: findings from the REasons for geographic and racial differences in stroke (REGARDS) study. J Am Geriatr Soc 62:S149

11. Desmet C, Beguin C, Swine C, Jadoul M (2005) Falls in hemodialysis patients: prospective study of incidence, risk factors, and complications. Am J Kidney Dis 45(1):148-153

12. Elliott MJ, James MT, Quinn RR, Ravani P, Tonelli M, PalaciosDerflingher L et al (2013) Estimated GFR and fracture risk: a population-based study. Clin J Am Soc Nephrol 8(8):1367-1376

13. Arneson TJ, Li S, Liu J, Kilpatrick RD, Newsome BB, St Peter WL (2013) Trends in hip fracture rates in US hemodialysis patients, 1993-2010. Am J Kidney Dis 62(4):747-754

14. Alem AM, Sherrard DJ, Gillen DL, Weiss NS, Beresford SA, Heckbert SR, Wong C, Stehman-Breen C (2000) Increased risk of hip fracture among patients with end-stage renal disease. Kidney Int 58(1):396-399

15. Atteritano M, Di Mauro E, Canale V, Bruzzese AM, Ricciardi CA, Cernaro V et al (2017) Higher serum sclerostin levels and insufficiency of vitamin D are strongly associated with vertebral fractures in hemodialysis patients: a case control study. Osteoporos Int 28(2): $577-584$

16. Hansen D, Olesen JB, Gislason GH, Abrahamsen B, Hommel K (2016) Risk of fracture in adults on renal replacement therapy: a Danish national cohort study. Nephrol Dial Transplant 31(10): 1654-1662

17. Maravic M, Ostertag A, Torres PU, Cohen-Solal M (2014) Incidence and risk factors for hip fractures in dialysis patients. Osteoporos Int 25(1):159-165

18. Coco M, Rush H (2000) Increased incidence of hip fractures in dialysis patients with low serum parathyroid hormone. Am J Kidney Dis 36(6):1115-1121

19. Racic M, Petkovic N, Bogicevic K, Maric I, Matovic J, Pejovic V et al (2015) Comprehensive geriatric assessment: comparison of elderly hemodialysis patients and primary care patients. Ren Fail 37(7):1126-1131

20. Wakasugi M, Kazama JJ, Taniguchi M, Wada A, Iseki K, Tsubakihara Y, Narita I (2013) Increased risk of hip fracture among Japanese hemodialysis patients. J Bone Miner Metab 31(3):315321

21. Bowling CB, Bromfield SG, Colantonio LD, Gutierrez OM, Shimbo D, Reynolds K et al (2016) Association of reduced eGFR and Albuminuria with serious fall injuries among older adults. Clin J Am Soc Nephrol 11(7):1236-1243

22. Chen H, Lips P, Vervloet MG, van Schoor NM, de Jongh RT (2018) Association of renal function with bone mineral density and fracture risk in the Longitudinal Aging Study Amsterdam. Osteoporos Int 29(9):2129-2138

23. Dukas LC, Schacht E, Mazor Z, Stähelin HB (2005) A new significant and independent risk factor for falls in elderly men and women: A low creatinine clearance of less than $65 \mathrm{ml} / \mathrm{min}$. Osteoporos Int 16(3):332-338

24. Dukas L, Schacht E, Stähelin HB (2005) In elderly men and women treated for osteoporosis a low creatinine clearance of $<65 \mathrm{ml} / \mathrm{min}$ is a risk factor for falls and fractures. Osteoporos Int 16(12):16831690
25. Hall RK, Landerman LR, O'Hare AM, Anderson RA, ColonEmeric CS, Erman LR et al (2015) Chronic kidney disease and recurrent falls in nursing home residents: a retrospective cohort study. Geriatr Nurs 36(2):136-141

26. Kistler BM, Khubchandani J, Jakubowicz G, Wilund K, Sosnoff J (2018) Falls and fall-related injuries among US adults aged 65 or older with chronic kidney disease. Prev Chronic Dis 15(6):1-9

27. Rafiq M, McGovern A, Jones S, Harris K, Tomson C, Gallagher H, de Lusignan S (2014) Falls in the elderly were predicted opportunistically using a decision tree and systematically using a databasedriven screening tool. J Clin Epidemiol 67(8):877-886

28. Rothenbacher D, Klenk J, Denkinger MD, Herbolsheimer F, Nikolaus T, Peter R et al (2014) Prospective evaluation of renal function, serum vitamin D level, and risk of fall and fracture in community-dwelling elderly subjects. Osteoporos Int 25(3):923932

29. Naylor KL, McArthur E, Leslie WD, Fraser L-AA, Jamal SA, Cadarette SM et al (2014) The three-year incidence of fracture in chronic kidney disease. Kidney Int 86(4):810-818

30. Dooley AC, Weiss NS, Kestenbaum B (2008) Increased risk of hip fracture among men with CKD. Am J Kidney Dis 51(1):38-44

31. Ensrud KE, Lui LY, Taylor BC, Ishani A, Shlipak MG, Stone KL et al (2007) Renal function and risk of hip and vertebral fractures in older women. Arch Intern Med 167(2):133-139

32. Ensrud KE, Parimi N, Fink HA, Ishani A, Taylor BC, Steffes M et al (2014) Estimated GFR and risk of hip fracture in older men: comparison of associations using cystatin $\mathrm{C}$ and creatinine. Am J Kidney Dis 63(1):31-39

33. Fried LF, Biggs ML, Shlipak MG, Seliger S, Kestenbaum B, Stehman-Breen C et al (2007) Association of kidney function with incident hip fracture in older adults. J Am Soc Nephrol 18(1):282286

34. Iwagami M, Caplin B, Smeeth L, Tomlinson LA, Nitsch D (2018) Chronic kidney disease and cause-specific hospitalisation: a matched cohort study using primary and secondary care patient data. Br J Gen Pract 68:e512-e523

35. Kim SM, Long J, Montez-Rath M, Leonard M, Chertow GM (2016) Hip fracture in patients with non-dialysis-requiring chronic kidney disease. J Bone Miner Res 31(10):1803-1809

36. Nickolas TL, McMahon DJ, Shane E (2006) Relationship between moderate to severe kidney disease and hip fracture in the United States. J Am Soc Nephrol 17(11):3223-3232

37. Perez-Saez MJ, Prieto-Alhambra D, Barrios C, Crespo M, Redondo D, Nogues X et al (2015) Increased hip fracture and mortality in chronic kidney disease individuals: the importance of competing risks. Bone. 73:154-159

38. Robertson L, Black C, Fluck N, Gordon S, Hollick R, Nguyen H et al (2018) Hip fracture incidence and mortality in chronic kidney disease: the GLOMMS-II record linkage cohort study. BMJ Open 8(4): $\mathrm{e} 020312$

39. LaCroix AZA, Lee JSJ, Wu L, Cauley JA, Shlipak MMG, Ott SM et al (2008) Cystatin-C, renal function, and incidence of hip fracture in postmenopausal women. J Am Geriatr Soc 56(8):1434-1441

40. Kaji H, Yamauchi M, Yamaguchi T, Shigematsu T, Sugimoto T (2010) Mild renal dysfunction is a risk factor for a decrease in bone mineral density and vertebral fractures in Japanese postmenopausal women. J Clin Endocrinol Metab 95(10):4635-4642

41. Mishima T, Motoyama K, Imanishi Y, Hamamoto K, Nagata Y, Yamada S, Kuriyama N, Watanabe Y, Emoto M, Inaba M (2014) Decreased cortical thickness, as estimated by a newly developed ultrasound device, as a risk for vertebral fracture in type 2 diabetes mellitus patients with eGFR of less than $60 \mathrm{~mL} / \mathrm{min} / 1.73 \mathrm{~m} 2$. Osteoporos Int 26(1):229-236

42. Daya N, Voskertchian A, Schneider ALC, Ballew S, McAdams DeMarco M, Coresh J, Appel LJ, Selvin E, Grams ME (2016) 
Kidney function and fracture risk: the Atherosclerosis Risk in Communities (ARIC) study. Am J Kidney Dis 67(2):218-226

43. Ensrud KE, Barbour K, Canales MT, Danielson ME, Boudreau RM, Bauer DC, Lacroix AZ, Ishani A, Jackson RD, Robbins JA, Cauley JA (2012) Renal function and nonvertebral fracture risk in multiethnic women: the Women's Health Initiative (WHI). Osteoporos Int 23(3):887-899

44. Hall RK, Sloane R, Pieper C, Van Houtven C, LaFleur J, Adler R et al (2018) Competing risks of fracture and death in older adults with chronic kidney disease. J Am Geriatr Soc 66(3):532-538

45. Kinsella S, Chavrimootoo S, Molloy MG, Eustace JA (2010) Moderate chronic kidney disease in women is associated with fracture occurrence independently of osteoporosis. Nephron Clin Pract 116(3):c256-c262

46. Kurajoh M, Inaba M, Nagata Y, Yamada S, Imanishi Y, Emoto M (2018) Association of cystatin C- and creatinine-based eGFR with osteoporotic fracture in Japanese postmenopausal women with osteoporosis: sarcopenia as risk for fracture. J Bone Miner Metab 123456789:1-10

47. Liao KM, Liang FW, Li CY (2016) Risks of all-cause and sitespecific fractures among hospitalized patients with COPD. Med (United States) 95(40):e5070

48. Yenchek RH, Ix JH, Shlipak MG, Bauer DC, Rianon NJ, Kritchevsky SB, Harris TB, Newman AB, Cauley JA, Fried LF, Health, Aging, and Body Composition Study (2012) Bone mineral density and fracture risk in older individuals with CKD. Clin J Am Soc Nephrol 7(7):1130-1136

49. Naylor KL, Garg AX, Zou G, Langsetmo L, Leslie WD, Fraser LA, Adachi JD, Morin S, Goltzman D, Lentle B, Jackson SA, Josse RG, Jamal SA (2015) Comparison of fracture risk prediction among individuals with reduced and normal kidney function. Clin J Am Soc Nephrol 10(4):646-653

50. McCarthy JT, Rule AD, Achenbach SJ, Bergstralh EJ, Khosla S, Melton LJ 3rd. (2008) Use of renal function measurements for assessing fracture risk in postmenopausal women. Mayo Clin Proc 83(11):1231-1239

51. Ensrud KE (2007) Renal function and risk of hip and vertebral fractures in older women. Arch Intern Med 167(2):133-139

52. Elder G (2002) Pathophysiology and recent advances in the management of renal osteodystrophy. J Bone Miner Res 17(12):20942105
53. Kendler DL, Bauer DC, Davison KS, Dian L, Hanley DA, Harris ST et al (2016) Vertebral fractures: clinical importance and management. Am J Med 129(2):221.e1-221.e10

54. Deandrea S, Lucenteforte E, Bravi F, Foschi R, La Vecchia C, Negri E (2010) Risk factors for falls in community-dwelling older people. Epidemiology. 21(5):658-668

55. Jansen S, Bhangu J, de Rooij S, Daams J, Kenny RA, van der Velde N (2016) The association of cardiovascular disorders and falls: a systematic review. J Am Med Dir Assoc 17(3):193-199

56. Moorthi RN, Avin KG (2017) Clinical relevance of sarcopenia in chronic kidney disease. Curr Opin Nephrol Hypertens 26(3):219 228

57. Ketteler M, Block GA, Evenepoel P, Fukagawa M, Herzog CA, McCann L, Moe SM, Shroff R, Tonelli MA, Toussaint ND, Vervloet MG, Leonard MB (2018) Diagnosis, evaluation, prevention, and treatment of chronic kidney disease-mineral and bone disorder: synopsis of the kidney disease: Improving global outcomes 2017 clinical practice guideline update. Ann Intern Med 168(6):422-430

58. CBO (2011) Richtlijn Osteoporose en fractuurpreventie. https:// www.volksgezondheidenzorg.info/bestanden/documenten/cborichtlijn-osteoporose-enfractuurpreventie-2011. Published 2011. Accessed 27 May 2019

59. Stevens JA, Ballesteros MF, Mack KA, Rudd RA, DeCaro E, Adler $G$ (2012) Gender differences in seeking care for falls in the aged medicare population. Am J Prev Med 43(1):59-62

60. Nussbaum J (2013) Fall prevention, reduced morbidity, and improved functional outcome measures in frail patients with end stage kidney disease undergoing a skilled physical therapy program: The prohealth experience. Blood Purif 35(1):157-158

61. Chang JT, Morton SC, Rubenstein LZ, Mojica WA, Maglione M, Suttorp MJ et al (2004) Interventions for the prevention of falls in older adults: systematic review and meta-analysis of randomised clinical trials. Br Med J 328(March):680-687

62. Heung M, Adamowski T, Segal JH, Malani PN (2010) A successful approach to fall prevention in an outpatient hemodialysis center. Clin J Am Soc Nephrol 5(10):1775-1779

Publisher's note Springer Nature remains neutral with regard to jurisdictional claims in published maps and institutional affiliations. 